\title{
Acceptance of IWBs Instruction and Concomitant Behavior through Self-regulation Learning
}

\author{
Hsiang-jen Meng, Tsu-yin Wang
}

\begin{abstract}
The integration of interactive whiteboards into the classroom has been promoted as a key step in bridging the ICT age. The reason that interactive whiteboard enables students to access up-to-date information via interactive learning environment. This study was to investigate the perception of teachers regarding the impact of interactive whiteboards initiative. The technology acceptance model was used as the theoretical framework but self-regulated learning was added as a possible moderating factor. Data analysis was applied by SEM technique. The conclusions were: (1) there are highly recognitions on the perceived ease of use (PEU) and perceived usefulness (PU) ; (2) there is a strong behavior intention (BI) to use IWBs; (3) there are positive relationship between PEU, PU, and BI; (4) BI has a direct impact on the actual use (AU); (5) the strategy of selfregulated learning was found to moderate the relationship between $\mathrm{BI}$ and $\mathrm{AU}$.
\end{abstract}

Index Terms-interactive whiteboard, technology acceptance model, sel-regulation learning

\section{INTRODUCTION}

In the age of ICT, the digitalized products have become an indispensable part of personal life no matter on living, learning, and working. Of course, one urgent task of teachers and/or teacher educators should recognize this situation and endeavors to improve students' learning ability through the utilization of digital channels. Taiwan's Ministry of Education had well known this trend in the middle 80's. The "General Guidelines of Grade 1-9 Curriculum of Elementary and Junior High School Education" published in 2001[1] clearly state that ICT education should be incorporated into all curricula, demanding specifically that students should have the ICT literacy of "knowing" and "doing". Teachers are capable of applying ICT to more than $20 \%$ of teaching activities [2]. According to the White Paper on IT in K-12 Education, each teacher's ICT proficiency should expect to satisfy the National Educational Technology Standards for Teacher (NETS for teachers, NETS $\bullet$ T). Additionally, Studies have pointed out that the key factor in the promotion of ICT lies in the guidance of curriculum and teaching rather than the technology itself [3] [4]. Thus, it is necessary to study the attitude of teachers toward ICT learning environment.

In 2009, the Taiwan government has budgeted for the renewal of computer facilities in elementary and middle schools of all cities as well as subsidizing schools to establish "e-learning based interactive whiteboards (IWBs) classrooms"
[5]. As IWB teaching systems are only in their beginning stage, teachers' habits of use and teaching efficacy need to be evaluated overtime. If IBW-based learning activities are to be comprehensively integrated, a couple issues need to be considered. The first thing needs to address the digital divide. The other is to introduce a student-oriented digital learning environment. Finally, teachers' behavioral use intentions and learning efficacy should be evaluated [6] [7]. According to PBS survey, it showed that a relatively lower proportion of teachers apply technological media to teaching, which seemed to be at odds with contemporary learning models [8]. Due to this lower expectation, the improvement of this situation requires teachers' acceptance and commitment of ICT [9] [10] [11]. When the new facilities arrived, schools might hold relevant teaching workshops and, expecting to enhance the use intention and teaching efficacy. Teachers also can gain experiences alternatively through their self-study efforts. Studies by Bandura [12] [13] indicated that a proper selfregulation leads to behavior modification. Accordingly, this study not only seeks to comprehend teachers' intention using IWBs instruction as a delivery tool, but also to explore the effect of teacher self-regulation learning. As we knew, although ICT is a key, it alone does not lead to better performance. In particular, modern teachers play the role of a facilitator rather than a follower, and therefore, how teachers handle newly developed educational technology and lead students to the next generation of learning is critical. The objectives of the paper are:

1. to study the relationship between perceived ease of use and behavior intention to IWBs teaching.

2. to study the relationship between perceived usefulness and behavior intention to IWBs teaching.

3 . to study the relationship between behavior intention and actual use of IWBs teaching.

4. to study the moderating impact of self-reinforcement in the above mentioned relationship.

\section{THEORETICAL BACKGROUND}

\subsection{Technology Acceptance Model (TAM)}

The theory of technology acceptance model (TAM) was used to examine the impact of technology on user behavior. The theory of TAM [14] adapted the concepts of the theory of reasoned action (TRA) to predict user acceptance of ICT [15]. The purpose of TAM is to deal with the process of using technology, where perceived usefulness (PU) and perceived ease of use (PEU) are two primary variables that affect an 
individual's intention to use a technology. PU refers to the belief that using the technology "would enhance his or her job performance", while PEU means that the user believes using the technology "would be free of effort" [14]. The beliefattitude-intention-behavior causal chain would determine a user's attitudes toward using the technology which in turn shapes behavioral intentions (BI) and actual use (AU) (see Figure 1). Both PU and PEU directly influence the individual's attitude toward use the technology. Attitude and $\mathrm{PU}$, in turn, predict the user intention. Otherwise, PE will directly impact PU as well.

As a result, TAM is an oft applied theory in studies on user acceptance of technology [16] and demonstrated the validity of TAM across a wide range of ICT [17] [18] [19]. The TAM has emerged as one of the most important theoretical models toward understanding ICT usage and acceptance behavior. However, this model is suitable for utilization of new information system [20] [21].

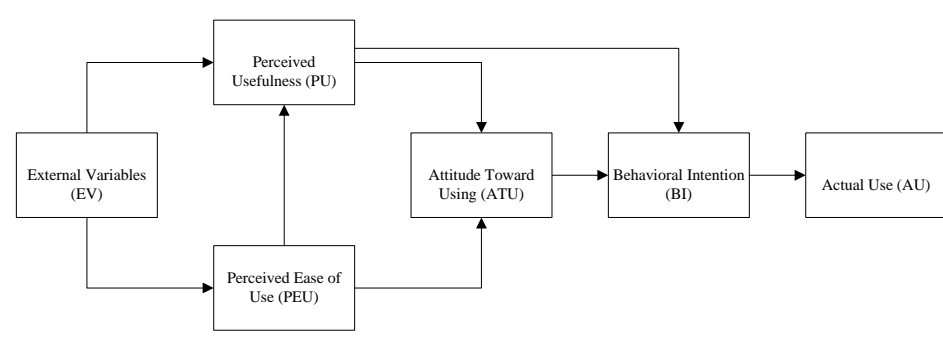

Figure1. Technology acceptance model [14]

\subsection{Self-regulation learning}

Nowadays, self-regulated learning (SRL) has emerged as an important educational issue [22] [23] [24]. The concept of self regulation was based on the theory of social learning [25]. Achieving the effective regulation of emotion is one of the most important aspects of personality and social development. Under naturalistic condition, self-regulation occurs within a social context [26]. That is, people continually observe the behavior of others on which it is rewards, ignored, or punished. From the perspective of social learning theory, people are seen as capable of operating some control abilities to their own behaviors [27]. In other words, Human behavior is extensively motivated and regulated by the ongoing exercise of selfinfluence [28]. The definition of self-regulation refers to the degree to which learners are meta-cognitively, motivationally, and behaviorally active participants in their own learning process [29]. In addition, self-regulation can be defined as selfgenerated thought, feeling, and actions for attaining academic goals [30]. Furthermore, SRL encompasses the self-efficacy mechanism, which plays a central role in the exercise of personal management by its strong impact on thought, affect, motivation, and action. The construct of SRL is manifested in the active monitoring and regulation of a number of different learning processes [31]. If cognitive activities are specific strategies to accomplish goals, meta-cognitive strategies are monitor and reflection to accomplish goals. Same viewpoint by Goldfried \& Merbaum [32] indicated that the major selfregulative mechanism operates through three principal sub- functions: self-monitoring, self-determination, and selfevaluation. Thus, individuals can regulate their behavior by making self-prescribed and self-reward. The self-regulative system is also involved in moral conduct although compared to the achievement domain, in the moral domain the evaluative standards are more stable, the judgmental factors more varied and complex, and the affective self-reactions more intense. In practice, self-regulation may involve increasing, maintaining, or decreasing both negative and positive emotions. The strategies of self-regulation frequently are adopted intentionally, sometimes with careful though about what would effectively influence the particular state being experienced. There is evidence that learners who have positive self-regulation beliefs are more likely to work harder, persist, and eventually achieve at higher levels [33]. SRL skills are critical for students to succeed in learning not only in traditional learning environments, but also in e-based learning environments. This definition fits the purpose of this article in that recognizes that self-regulation applies not just to cognition but also to motivational beliefs and overt behavior in the future learning activities.

\section{RESEARCH METHOD}

This study conducted a survey to understand elementary and middle school teachers' acceptance of IWBs instruction. The hypothetical model was established based on TAM and the question items were adopted from Davis [20] and constructed according to PU, PEU, BI and AU. We used a Likert 7 point scales, ranging from highly agree to highly disagree. The research subject for this survey was seed teachers who have completed in-site training from Pingtung remote district 114 elementary and middle schools in Taiwan. A total number of 570 questionnaires were distributed and 355 valid samples were collected with $62.28 \%$. The interviewed teachers were self-report that it was a self-regulation learner or non self-regulation learner. Among them, the teacher split was 113 SRL members and 242 non-SRL members. Structural equation modeling (SEM) is a statistical approach for examining the causal relationship and testing the hypotheses between the observed and latent variables in a research model [34]. The advantages of SEM is that estimate a measurement and structure model, and achieve a good model fit after analysis and modification. The statistical software SPSS 17.0 and AMOS 17.0 were the analytical tools of this study. The SEM analysis procedure was: (1) examine if the hypothetical model is accepted by confirmatory factor analysis (CFA), (2) examine the latent relation and model fit of SEM, (3) conduct path analysis model, and (4) analyze the moderating impact of teacher self-regulation. According to the TAM theory, PEU should have impact on PU, and have further impact on BI and AU.

As presented in Figure2, this research hypothesized that: H1: PEU has a positive related to $P U$

H2: $P U$ has a positive related to $B I$

H3: $P E U$ has a positive related to $B I$

H4: $B I$ has a positive related to $A U$ H5: SRL has direct impact on BI and AU. 


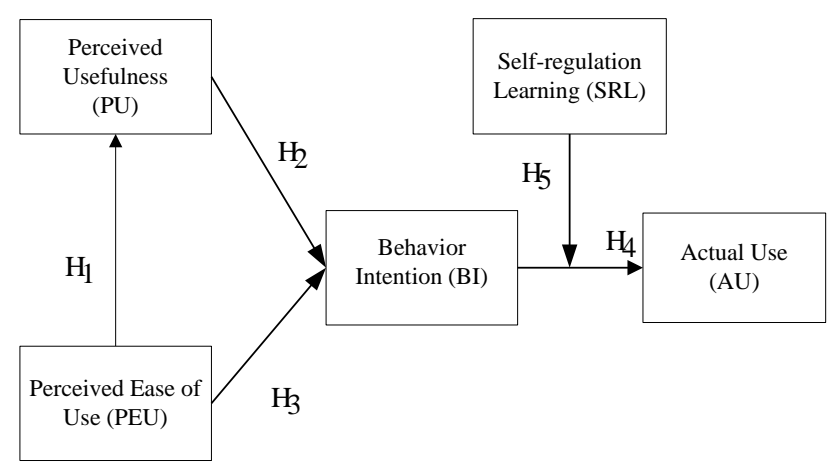

Figure2. The proposed research model

\section{ANALYTICAL RESULTS}

The descriptive statistics show that respondents all have a high level of acceptance of IWBs instruction, with an average score between 4.85 and 5.17. BI has the highest score while AU the lowest. In order to present the measure effects between latent variables and observed variables as well as the casual relation between latent variables, this study verified the hypothetical model using SEM, a process which involved three parts.

\subsection{Confirmatory Factor Analysis (CFA)}

This study used CFA to examine the covariance relation between the observed variables and latent variables as well as calculating the convergent and discrimination validity of the CFA model, as shown in Table 1. CFA shows that the factor loading of estimated parameters of all observed variables is larger than 0.45 with its multiple correlation square larger than 0.2 , indicating convergent validity [35] [36]. Our model also satisfies the standard of discrimination validity, with each value between 0.78 and 0.81 . The standard was determined by the AVE root square value of each aspect being larger than $75 \%$ of the loading of the correlation coefficient of each aspect [37]. The composite reliability (CR) of this study was between 0.83 and 0.86 and its average variance extracted (AVE) was between 0.61 and 0.66 , both larger than the suggested values of 0.6 and 0.5 [38]. The aforementioned figures show that all the observed variables in our research structure can reflect the constructed latent variables.

\subsection{Model Goodness of Fit}

Our research model comprised four aspects, and each aspect was measured by three to four questions. Analysis of the research model yielded the following indices: (1)the absolute fit measures of the overall model fit are $\chi^{2} / d f=3.372\left(\chi^{2}=\right.$ 205.715, df=561, $\mathrm{p}<.001), \mathrm{GFI}=.918, \mathrm{AGFI}=.877, \mathrm{SRMR}=.052$, RMSEA $=.082$; $(2)$ the relative fit measures include $\mathrm{NFI}=.924$, $\mathrm{IFI}=.945$, CFI=.945, and RFI=.902; (3) the parsimonious fit measures include $\mathrm{PNFI}=.722, \mathrm{PCFI}=.739$ and $\mathrm{PGFI}=.615$. The comparison between sample data and the hypothetical model shows a satisfactory model fit. Figure 3 and Table 2 show that each path coefficient of our research hypotheses are significant and are accepted, providing support for all hypotheses 1 to 4 . In other words, acceptance of teachers of a IWBs teaching model shows positive response in the interactions among PEU, PU, BI and AU. The relations between PEU and PU (0.88) as well as between BI and AU (0.70) have the strongest explanatory power. In the overall model, perceptions can explain $56 \%$ and $49 \%$ of the variance in behavioral intention to use and actual system use.

Table 3 shows the impact of each latent variable, including the direct, indirect and total effects. Behavior intention to use (BI) is an outcome variable used to determine whether teachers are willing to adopt IWBs instruction. The table shows that determinant with the direct impact on BI is PEU $(\beta=.388)$, followed by perceived usefulness $(\beta=.384)$. In terms of the total effect of BI and PEU is .727 which represents the more teachers feeling that IWBs instruction is PEU, the stronger will be the intention to use IWBs instruction in the future. Moreover, $\mathrm{BI}$ has stronger direct impact to $\mathrm{AU}(\beta=.698)$.

TABLE1. Confirmatory Factor Analysis of the Model

\begin{tabular}{llllll}
\hline Observed Variables & $\boldsymbol{M}$ & $\boldsymbol{S D}$ & $\boldsymbol{S F L}$ & $\boldsymbol{C R}$ & $\boldsymbol{A} \boldsymbol{V E}$ \\
\hline Perceived Usefulness & $\mathbf{5 . 0 0}$ & & & $\mathbf{. 8 6}$ & $\mathbf{. 6 1}$ \\
instruction & 5.04 & 1.16 & $.86^{*}$ & & \\
instruction & 5.19 & 1.20 & $.82^{*}$ & & \\
instruction efficiency & 4.55 & 1.46 & $.73^{*}$ & & \\
instruction effective & 5.21 & 1.17 & $.86^{*}$ & & \\
\hline Perceived Ease of Use & $\mathbf{5 . 0 0}$ & & & $\mathbf{. 8 5}$ & $\mathbf{. 6 6}$ \\
learning easily & 5.16 & 1.13 & $.87^{*}$ & & \\
understanding easily & 5.02 & 1.17 & $.85^{*}$ & & \\
presenting easily & 4.82 & 1.30 & $.75^{*}$ & & \\
\hline Behavior Intention & $\mathbf{5 . 1 6}$ & & & $\mathbf{. 8 4}$ & $\mathbf{. 6 3}$ \\
try to use & 4.77 & 1.34 & $.73^{*}$ & & \\
need to use & 5.51 & 1.12 & $.74^{*}$ & & \\
like to use & 5.21 & 1.18 & $.51^{*}$ & & \\
\hline Actual Usage & $\mathbf{4 . 8 4}$ & & & $\mathbf{. 8 3}$ & $\mathbf{. 6 2}$ \\
use anyway possibly & 5.18 & 1.27 & $.76^{*}$ & & \\
use anyhow possibly & 4.52 & 1.40 & $.85^{*}$ & & \\
use appropriately & 4.82 & 1.42 & $.74^{*}$ & & \\
\hline
\end{tabular}

Note: $M$ : mean; $S D$ : standard deviation, $S F L$ : standardized factor loading, $C R$ : composite reliability, $A V \mathrm{E}$ : average of variance extracted $* p<.05$

TABLE 2. Results of Path Analysis

\begin{tabular}{lllll}
\hline Hypotheses & paths & SRW & SE & $t$-value \\
$\mathrm{H}_{1}$ & PEU $\rightarrow$ PU & .88 & .78 & $17.437 * * *$ \\
$\mathrm{H}_{2}$ & $\mathrm{PU} \rightarrow \mathrm{BI}$ & .38 & .56 & $2.572^{* *}$ \\
$\mathrm{H}_{3}$ & $\mathrm{PEU} \rightarrow \mathrm{BI}$ & .39 & .56 & $2.576^{* *}$ \\
$\mathrm{H}_{4}$ & $\mathrm{BI} \rightarrow \mathrm{AU}$ & .70 & .49 & $8.329 * * *$ \\
\hline
\end{tabular}

Note: SRW: standardized regression weights, SE: standard error ** $p<.01$, *** $p<.001$ 


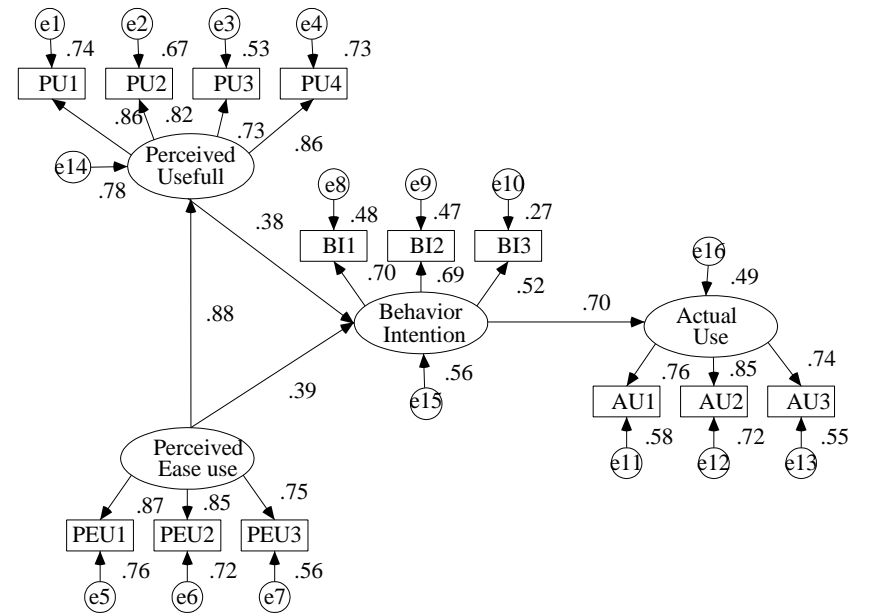

Figure3. Results of structural modeling analysis

TABLE 3. The effect size of latent variables

\begin{tabular}{ccccc}
\hline $\begin{array}{c}\text { Dependent } \\
\text { Variables }\end{array}$ & $\begin{array}{c}\text { Independent } \\
\text { Variables }\end{array}$ & $\begin{array}{c}\text { Direct } \\
\text { effect }\end{array}$ & $\begin{array}{c}\text { Indirect } \\
\text { effect }\end{array}$ & $\begin{array}{c}\text { Total } \\
\text { Effect }\end{array}$ \\
\hline BI & PEU & .388 & .339 & .727 \\
& PU & .384 & - & .384 \\
AU & BI & .698 & - & .698 \\
\hline
\end{tabular}

\subsection{The Analysis of Moderating Effects}

In order to investigate moderating effects, the current study followed the steps for examination of moderators as suggested by Jöreskog \& Sörbom [39]. The total sample was divided into SRL and non-SRL groups. The group split was 113 SRL and 242 non-SRL teachers. Before testing for the moderation effect of SRL, it was deemed important to test whether there are any differences in BI and AU of the respondents. Based on Dabholkar and Bagozzi recommendation [40], the research model associated with multiple-group analysis using SEM is to be constrained in terms of error variances explained by latent variables and path coefficients between latent variables. Table 4 shows there are significant different between SRL and non-SRL group models based on the comparison of measurement weights, structural weights, and structural covariances. As hypothesized in the SRL moderator models and this study $\mathrm{H}_{5}$, table 5 indicates that the SRL group teachers tend to be influenced by their learning strategy $(\beta=.88)$ greater than non-SRL teachers $(\beta=.62)$. As a result, SRL strategy can be proved as a moderator to this study on which the use of self-regulation learning strategy can gain impact the relationship between BI and actual use AU toward IWBs instruction.

TABLE 4. Multiple-group analysis

\begin{tabular}{lrrr}
\hline \multicolumn{1}{c}{ Model } & $D F$ & $C M I N$ & $P$ \\
\hline Measurement weights & 9 & $18.254^{*}$ & .032 \\
Structural weights & 13 & $22.455^{*}$ & .049 \\
Structural covariances & 14 & $23.018^{*}$ & .041 \\
\hline$* p<.05$ & & &
\end{tabular}

TABLE 5. Taxonomy of SRL moderating effect

\begin{tabular}{crrr}
\hline & $\begin{array}{c}\text { Base Model } \\
(\mathrm{n}=355)\end{array}$ & \multicolumn{2}{c}{ Moderator Model } \\
\cline { 3 - 4 } Path & & \multicolumn{1}{c}{$\begin{array}{c}\text { SRL } \\
(\mathrm{n}=113)\end{array}$} & $\begin{array}{c}\text { Non }-\mathrm{SRL} \\
(\mathrm{n}=242)\end{array}$ \\
\hline $\mathrm{PEU} \rightarrow \mathrm{PU}$ & $.88 * * *$ & $.89 * * *$ & $.88 * * *$ \\
$\mathrm{PU} \rightarrow \mathrm{BI}$ & $.38 * *$ & $.40 * *$ & $.34 *$ \\
$\mathrm{PEU} \rightarrow \mathrm{BI}$ & $.40 * *$ & $.38^{*}:$ & $.42 * *$ \\
$\mathrm{BI} \rightarrow \mathrm{AU}$ & $.70 * * *$ & $.88^{* * *}$ & $.62 * * *$ \\
\hline$* p<.05, * * p<.01, * * * p<.001$ & & \\
\end{tabular}

It was found that perceived ease of use and perceived usefulness both have significant impact on the intention to use and usage of IWBs instruction. These findings are consistent with the previous research findings [41] [42] [43]. The IWBs system needs to be perceived easy to use and usefulness before users will think about using it. As teachers are faced to use the new-coming IWBs, it also can be observed that PEU is more important than PU in determining BI. Hence, teachers are more concerned the IWBs easier to use or not rather than just told them the benefits of IWBs. Of course, a well-developed educational technology should be perceived to be better to have than to be without. The study also concurs with the theory of TAM that is applicable in the adoption of IWBs instruction and the two beliefs which are PEU and PU are served as strong predictors of IWBs usage. The finding of this study can be used by school administration authorities to encourage the acceptance and usage of IWBs instruction for current teachers. The related educational policies can focus on the ease of use and usefulness when encouraging teachers to use a given new IWBs teaching tool. They should give teachers some of on-thejob training in order to fully utilize and operate the IWBs in their own classroom. In addition, the study also provided a practical support that the relationship between BI and AU is moderated by the self-regulated learning strategies. To enhance higher usage of IWBs instruction, the self-regulated learning will become a necessary step before actual usage of IWBs in their actual teaching operation.

\section{REFERENCES}

[1] Ministry of Education. General Guidelines of Grade 1-9 Curriculum of Elementary and Junior High School Education. Taipei, Taiwan, 1998.

[2] Ministry of Education. The Blueprint of ICT education in Taiwan. Taipei, Taiwan ,2008.

[3] K. Robert, \& A. Lenz, "Cowboys with cameras: an interactive expedition," British Journal of Educational Technology, vol. 40, no.1, pp. 119-134.

[4] C. R. Graham, "Blended learning systems: Definition, current trends, and future directions," The handbook of blended learning: Global perspectives, local designs, 2006, pp. 3-21.

[5] Ministry of Education, Excellent Equal Digital Education Project. Taipei, Taiwan, 2011.

[6] S. Higgins, G. Beauchamp, \& D. Miller, "Reviewing the literature on interactive whiteboards," Learning, Media and Technology, vol. 32, no. 1, 2007, pp. 213-225.

[7] D. Glover, D. Miller, D. Averis, \& V. Door, "The evolution of an effective pedagogy for teachers using the interactive whiteboard in mathematics and modern languages: An empirical analysis from the 
secondary sector," Learning, Media and Technology, vol. 32, no. 1, 2007, pp. 5-20.

[8] PBS \& Grunwald Associates LLC, Deepening Connections: Teachers Increasingly Rely on Media and Technology. Bethesda, Maryland, USA, 2010.

[9] F. Saltan, K. Arslan, \& A. GöK, "Teachers' acceptance of interactive white boards: A case study," In D. Gibson \& Dodge (Eds.). Proceedings of Society for Information Technology \& Teacher Education International Conference 2010, Chesapeake, VA: AACE, 2010, pp. 2360-2365.

[10] S. Tgirvakdsen, G. Egeberg, G. Petersen, \& L. Vavlk, "Digital dysfunctions in primary school: A pilot study," Computer \& Education, vol. 56, no. 1, 2011, pp. 312-319.

[11] Y. Turel, "Developing teachers' utilization of interactive whiteboards," In D. Gibson \& B. Dodge (Eds.), Proceedings of Society for Information Technology \& Teacher Education International Conference 2010. Chesapeake, VA: AACE, 2010, pp. 3049-3054.

[12] A. Bandura, "Vicarious and self-reinforcement processes," The nature of reinforcement, 1971, pp. 228-278.

[13] A. Bandura, "Self-reinforcement: Theoretical and methodological considerations," Behaviorism, vol. 4, no. 2, 1976, pp. 135-155.

[14] F. D. Davis, A Technology Acceptance Model for Empirically Testing New End-use Information Systems: Theory and Results. Doctoral dissertation, MIT Sloan School of Management, Cambridge, MA, 1986.

[15] I. Ajzen, "The theory of planned behavior," Organizational Behavior and Human Decision Processes, vol. 50, 1991, pp. 179-211.

[16] V. Venkatesh, \& F. D. Davis, "A model of the antecedents of perceived ease of use: Development and Test," Decision Sciences, vol. 27, no. 3, 1996, pp. 451-481.

[17] P. Y. K. Chau, \& P. J. Hu, "Examining a model of information technology acceptance by individual professionals: An exploratory study," Journal of Management Information Systems, vol. 18, no. 4, 2002, pp. 191-229.

[18] P. J. Hu, P. Y. K. Chau, O. R. L. Sheng, \& K. Y. Tam, "Examining the technology acceptance model using physician acceptance of telemedicine technology," Journal of Management Information Systems, vol. 16, no. 2, 1999, pp. 91-112.

[19] P. Legris, J. Ingham, \& P. Collerette, "Why do people use information technology? A critical review of the technology acceptance model," Information \& Management, vol. 40, no. 3, 2003, pp. 191-204.

[20] F. D. Davis, "Perceive usefulness, perceived of ease of use, and end user acceptance of information technology," MIS Quarterly, vol. 13, 1989, pp. 318-339.

[21] F. D. Davis, R. P. Bagozzi, \& P. R. Warshaw, "User acceptance of computer technology: A comparison of two theoretical models," Management Science, vol. 35, no. 8, 1989, pp. 982-1003.

[22] M. Boekaerts, "Self-regulated learning: Where we are today," International Journal of Educational Research, vol. 31, 1999, pp. 445457.

[23] D. Schunk, Learning theories: An educational perspective. New Jersey: Prentice-Hall, 2000

[24] D. Schunk, \& B. Zimmerman, Self-regulated learning: From teaching to self-reflective practice. New York: Guilford Press, 1998.

[25] A. Bandura, "Social-learning theory of identificatory processes," In D A. Goslin(Ed.),Handbook of socialization theory and research. Chicago: Rand McNally,1969, pp. 213-262.

[26] A. Bandura, "Vicarious and self-reinforcement processes," The nature of reinforcement, 1971, pp. 228-278

[27] A. Bandura, "Self-reinforcement: Theoretical and methodological considerations," Behaviorism, vol. 4, no. 2, 1976. pp 135-155.

[28] P. R. Pintrich, \& D. H. Schunk, Motivation in education: Theory, research, and applications(2nd ed.). Upper Saddle,NJ:Prentice-hall, 2002.
[29] B. J. Zimmerman, "Dimensions of academic self-regulation: A conceptual framework for education," Self-regulation of learning and performance: Issues and educational applications, vol. 1, 1994, pp. 3321.

[30] B. J. Zimmerman, "Academic studying and the development of personal skill: A self-regulatory perspective," Educational psychologist, vol. 33 , 1998, pp. 73-86

[31] P. Pintrich, \& A. Zusho, "Student motivation and self-regulated learning in the college classroom," The scholarship of teaching and learning in higher education: An evidence-based perspective, 2007, pp. 731-810.

[32] M. R. Goldfried, \& M. Merbaum, Behavior change through self-control. Oxford, England: Holt, Rinehart \& Winston, 1973

[33] E. A. Linnenbrink, \& P. R. Pintrich, "Motivation as an enabler for academic success," School Psychology Review, vol. 31, no. 3, 2002, pp. 313-327.

[34] B. Byrne, Structural Equation Modeling with AMOS: Basic Concepts, Applications, and Programming. Mahwah, NJ: Lawrence Erlbaum Associate, 2001.

[35] P. M. Bentler, \& F. J. C. Wu, EQS/Windows User's Guide. Los Angeles: BMDP Statistical Software, 1993.

[36] K. G. Jöreskog, \& D. Sörbom, LISREL 7: A Guide to the Program and Application. Chicago: SPSS Inc, 1989.

[37] J. F. Jr. Hairs, R. E. Anderson, R. L. Tatham, \&, W. C. Black, Multivariate Data Analysis (5th ed.). NY: Macmillan, 1998.

[38] R. P. Bagozzi, \& Y. Yi, "On the evaluation of structural equation models," Journal of the Academy of Marketing Science, vol. 16, no. 1, 1988, pp. 74-79.

[39] K. G. Joreskog, \& D. Sorbom, LISREL 8 user's reference guide. Lincolnwood, IL:Scientific Software International, 1996

[40] P. A. Dabholkar, \& R. P. Bagozzi, "An attitudinal model of technologybased self-service: moderating effects of consumer traits and situational factors". Journal of the academy of marketing science, vol. 30, no. 3 , 2002, pp. 184-201.

[41] N. O. Ndubisi, "Integrating the moderation effect of entrepreneurial qualities into the Tam model and treatment of potential confounding factors," Journal of Information Science and Technology, vol. 2, no. 1, 2005, pp. $28-48$

[42] , \& L. May-Chiun, "Impact of shared beliefs on perceived usefulness and ease of use in the implementation of an enterprise resource planning system," Management Research News, vol. 30, no. 6, 2007, pp. 420-431

[43] T. Ramayah, "The role of voluntariness in distance education students' usage of a course website," The Turkish Online Journal of Educational Technology, vol. 3, no. 3, 2010, pp. 96-105.

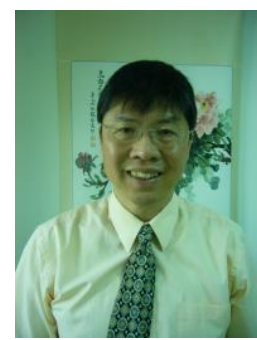

Hsiang-jen Meng received his MS (1990) in engineering technology and Education Specialist (1991) from Pittsburg State University, Pittsburg, Kansas, USA. In 1995, he obtained his Ph. D. in industrial \& technology education from University of Missouri-Columbia, Columbia, Missouri, USA. He is currently an Associate Professor in Graduate Institute of Technological and Vocational Education at National Pingtung University of Science and Technology in Pingtung, Taiwan, where he has been teaching the theory and practice of vocational education, educational administration, and education policy and research. He has a strong interest in educational innovation to improve instructional strategies, such as e-learning and related application. He has published around 50 scientific and/or education papers in referred journal and conference proceedings.

Tsu-yin Wang received his $\mathrm{Ph} . \mathrm{D}$. in industrial \& technology education from University of Missouri-Columbia, Columbia, Missouri, USA. He is currently an Associate Professor in Department of Arts and Design at National Dong Hwa University in Hualian, Taiwan. 